\title{
The role of postoperative radiotherapy in hepatocellular carcinoma
}

\author{
Joongyo Lee, Jinsil Seong \\ Department of Radiation Oncology, Yonsei Cancer Center, Yonsei University College of Medicine, Seoul, South Korea \\ Correspondence to: Jinsil Seong, MD, PhD. Department of Radiation Oncology, Yonsei Cancer Center, Yonsei University College of Medicine, \\ Seoul, South Korea. Email: jsseong@yuhs.ac. \\ Comment on: Chen B, Wu JX, Cheng SH, et al. Phase 2 Study of Adjuvant Radiotherapy Following Narrow-Margin Hepatectomy in Patients With \\ HCC. Hepatology 2021;74:2595-604.
}

Submitted Nov 29, 2021. Accepted for publication Dec 09, 2021.

doi: $10.21037 / \mathrm{hbsn}-21-500$

View this article at: https://dx.doi.org/10.21037/hbsn-21-500

Surgery is the standard treatment for early-stage hepatocellular carcinoma (HCC). However, the application of surgery is frequently expanded in real-world practice beyond the early stage, involving even advanced HCC associated with vascular invasion (1). Two important issues arise when the scope of surgery in HCC is expanded: achieving $\mathrm{R} 0$ resection and preserving sufficient future remnant liver volume. These two issues often contradict each other in HCC with large size or vascular invasion because surgeons try to secure sufficient future remnant liver to avoid post-resection liver failure, thereby leading to narrow-margin hepatectomy.

The efficacy of postoperative adjuvant treatment in HCC has not been fully documented, with only a few reports on postoperative adjuvant transarterial chemoembolization (TACE) are available $(2,3)$. Yet, no level 1 evidence on whether postoperative adjuvant TACE can reduce recurrence and prolong survival exists to date.

Radiotherapy (RT), which has proven to be an effective postoperative adjuvant modality in most solid cancers, has not been fully demonstrated as a combination strategy with surgery in HCC. A randomized, open-label, multicenter controlled study published in 2019 showed improved survival upon administration of neoadjuvant RT for resectable HCC with portal vein tumor thrombus (PVTT) (4). However, evidence of postoperative RT following hepatectomy is still lacking, and only retrospective studies reporting improvement in survival after RT are available $(5,6)$. Although an open-label, randomized controlled trial showing survival benefit with postoperative $\mathrm{RT}$ in
HCC with PVTT has been reported, additional studies are needed due to its small size (52 patients) (7). In the past, the role of RT in HCC, including its postoperative aim, was underestimated concerning toxicity. However, recent developments in RT technology, such as intensitymodulated RT (IMRT), have led to the more accurate and precise delivery of high-dose radiation, thereby reducing unnecessary radiation exposure to the surrounding normal tissues.

A retrospective study reported the results of postoperative IMRT in 33 patients with narrow margins after hepatectomy in HCC (8). In that study, postoperative IMRT following narrow-margin hepatectomy improved survival, and no patient developed radiation-induced liver disease. Based on these results, a subsequent phase 2 clinical study was conducted; in 76 patients who underwent postoperative IMRT after narrow-margin hepatectomy, the 5 -year overall survival and disease-free survival (DFS) were $72.2 \%$ and $51.6 \%$, respectively, similar to those observed in patients undergoing wide-margin hepatectomy (9).

This study has a few strengths. First, the study was fairly homogenous regarding patient selection and treatment. Only patients with a surgical margin of less than $1.0 \mathrm{~cm}$ after hepatectomy were enrolled, and there was no lymph node metastasis in any patient. All patients were treated with IMRT. Target delineation was also set with 1.0 or $1.5 \mathrm{~cm}$ of margin depending on whether the major vascular structure was around the tumor bed, and similar dose schemes of 50-60 Gy in 25-30 fractions were prescribed.

Second, they suggested the definition of a narrow 
margin after hepatectomy that requires postoperative RT. Regarding surgical margins, a worse prognosis has been reported for less than $1.0 \mathrm{~cm}(10,11)$, and it is frequently associated with marginal recurrence $(12,13)$. This notion agrees with the necessity of postoperative RT, which is in accordance with the results of this study (9).

Finally, they emphasized the importance of microscopic vascular invasion (MVI) on the histological findings after surgery. MVI has received much attention in recent studies as a risk factor for recurrence along with surgical margins. MVI represents microemboli of HCC in the hepatic or portal vein around the adjacent tumor tissue and plays a crucial role in the recurrence and survival of HCC, as it is one of the most common residual micrometastases in the liver (14). In principle, RT planning sets three target volumes: gross tumor volume (GTV), clinical target volume (CTV), and planning target volume (PTV). By allowing sufficient CTV to plan and perform RT, the risk of recurrence can be reduced in patients with MVI. In the study by Chen et al. (9), the 3-year DFS of patients with MVI, which was $50 \%$, was higher than that reported in other studies that did not perform postoperative RT. Therefore, RT may be an appropriate postoperative treatment for patients with MVI.

Likewise, in most cancers, multidisciplinary management is key to successful oncologic outcomes in HCC. While we congratulate Chen and colleagues on this study, the efficacy of postoperative RT needs further validation through a phase 3 randomized trial.

\section{Acknowledgments}

Funding: None.

\section{Footnote}

Provenance and Peer Review: This article was commissioned by the editorial office, Hepatobiliary Surgery and Nutrition. The article did not undergo external peer review.

Conflicts of Interest: Both authors have completed the ICMJE uniform disclosure form (available at https://hbsn. amegroups.com/article/view/10.21037/hbsn-21-500/coif). The authors have no conflicts of interest to declare.

Ethical Statement: The authors are accountable for all aspects of the work in ensuring that questions related to the accuracy or integrity of any part of the work are appropriately investigated and resolved.

Open Access Statement: This is an Open Access article distributed in accordance with the Creative Commons Attribution-NonCommercial-NoDerivs 4.0 International License (CC BY-NC-ND 4.0), which permits the noncommercial replication and distribution of the article with the strict proviso that no changes or edits are made and the original work is properly cited (including links to both the formal publication through the relevant DOI and the license). See: https://creativecommons.org/licenses/by-nc-nd/4.0/.

\section{References}

1. Park JW, Chen M, Colombo M, et al. Global patterns of hepatocellular carcinoma management from diagnosis to death: the BRIDGE Study. Liver Int 2015;35:2155-66.

2. Liao $M$, Zhu Z, Wang $\mathrm{H}$, et al. Adjuvant transarterial chemoembolization for patients after curative resection of hepatocellular carcinoma: a meta-analysis. Scand J Gastroenterol 2017;52:624-34.

3. Wang L, Ke Q, Deng M, et al. Adjuvant transarterial chemoembolization for patients with hepatocellular carcinoma after radical hepatectomy: a real world study. Scand J Gastroenterol 2019;54:1403-11.

4. Wei X, Jiang Y, Zhang X, et al. Neoadjuvant ThreeDimensional Conformal Radiotherapy for Resectable Hepatocellular Carcinoma With Portal Vein Tumor Thrombus: A Randomized, Open-Label, Multicenter Controlled Study. J Clin Oncol 2019;37:2141-51.

5. Wang L, Chen B, Li Z, et al. Optimal postoperative adjuvant treatment strategy for HBV-related hepatocellular carcinoma with microvascular invasion: a propensity score analysis. Onco Targets Ther 2019;12:1237-47.

6. Wang L, Wang W, Yao X, et al. Postoperative adjuvant radiotherapy is associated with improved survival in hepatocellular carcinoma with microvascular invasion. Oncotarget 2017;8:79971-81.

7. Sun J, Yang L, Shi J, et al. Postoperative adjuvant IMRT for patients with HCC and portal vein tumor thrombus: An open-label randomized controlled trial. Radiother Oncol 2019;140:20-5.

8. Wang WH, Wang Z, Wu JX, et al. Survival benefit with IMRT following narrow-margin hepatectomy in patients with hepatocellular carcinoma close to major vessels. Liver Int 2015;35:2603-10.

9. Chen B, Wu JX, Cheng SH, et al. Phase 2 Study of Adjuvant Radiotherapy Following Narrow-Margin 
Hepatectomy in Patients With HCC. Hepatology 2021;74:2595-604.

10. Shimada K, Sakamoto Y, Esaki M, et al. Role of the width of the surgical margin in a hepatectomy for small hepatocellular carcinomas eligible for percutaneous local ablative therapy. Am J Surg 2008;195:775-81.

11. Nara S, Shimada K, Sakamoto Y, et al. Prognostic impact of marginal resection for patients with solitary hepatocellular carcinoma: evidence from 570 hepatectomies. Surgery 2012;151:526-36.

12. Poon RT, Fan ST, Ng IO, et al. Significance of resection

Cite this article as: Lee $\mathrm{J}$, Seong $\mathrm{J}$. The role of postoperative radiotherapy in hepatocellular carcinoma. HepatoBiliary Surg Nutr 2022;11(1):123-125. doi: 10.21037/hbsn-21-500 margin in hepatectomy for hepatocellular carcinoma: A critical reappraisal. Ann Surg 2000;231:544-51.

13. Liu L, Shui Y, Yu Q, et al. Narrow-Margin Hepatectomy Resulted in Higher Recurrence and Lower Overall Survival for R0 Resection Hepatocellular Carcinoma. Front Oncol 2021;10:610636.

14. Zhang X, Li J, Shen F, et al. Significance of presence of microvascular invasion in specimens obtained after surgical treatment of hepatocellular carcinoma. J Gastroenterol Hepatol 2018;33:347-54. 